Journal of Experimental and Clinical Medicine https://dergipark.org.tr/omujecm

Case Report

$\mathrm{J}$ Exp Clin Med

2021; 38(3): 398-401

doi: $10.52142 /$ omujecm.38.3.39

\title{
Endoscopic vacuum assisted closure of gastrocutaneous fistula after sleeve gastrectomy combined with fibrin sealant
}

\author{
Jarosław CWALIŃSKI*®i, Jacek HERMANN®, Jacek PASZKOWSKIĐ, Tomasz BANASIEWICZ®
}

Department of General Endocrinological Surgery and Gastroenterological Oncology, Faculty of Medical Sciences, Poznan University, Poland

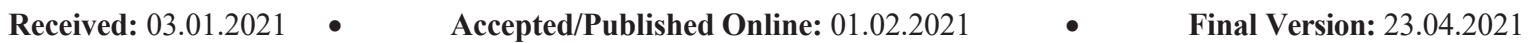

\begin{abstract}
Treatment of gastrointestinal fistulas after staple line leaks is difficult and non-invasive procedures such as endoclips, stents or endoscopic vacuum assisted closure (E-VAC) are sometimes not adequate. Fibrin sealants (FS) may promote healing, although today are used mainly to prevent anastomosis dehiscence within digestive tract. The authors present a 37-year-old female patient who developed a chronic gastrocutaneous fistula after sleeve gastrectomy for severe obesity treated successfully with a combination of E-VAC and a fibrin sealant. Long term peritoneal drainage, total parenteral nutrition, and antibiotic therapy for the next six weeks failed to close the leakage. Ultimately the fistula was closed after 6 changes of E-VAC and final implementation of a fibrin sealant. The duration of treatment was 81 days, including 34 days of E-VAC treatment and FS application. Complete closure of the fistula was visualized on gastroscopy six weeks after the treatment.
\end{abstract}

Keywords: E-VAC, E-NPWT, tissue sealant, fibrin glue, gastrocutaneous fistula

\section{Introduction}

Anastomotic leakage after bariatric surgery remains the most severe and a life-threatening complication related to high failure rate. Fistulas resulting from leaks can penetrate into the peritoneum, pleura or other organs and therefore they are a challenge to surgeons (Burgos et al., 2009; Campanile et al., 2013). The priority is effective drainage supported by endoscopic procedures, correction of fluid and electrolyte disturbances, and treatment of sepsis with appropriate antibiotics (Csendes et al., 2005; Campanile et al., 2013). The endoscopic interventions consisting of stent implantation or endoscopic vacuum assisted closure (E-VAC) showed their effectiveness in mild and early leakages (Borejsza-Wysocki et al., 2015; Hwang et al., 2016).

The authors present a patient with a successfully treated gastrocutaneous fistula following anastomotic rupture. That two-stage strategy based on the initial retraction of the fistula using an endoluminal vacuum dressing and then its final closure with fibrin tissue glue. The therapy described was performed in accordance with the principles of medical ethics and good medical practice. Patients provided informed written consent prior to all medical procedures and for the publication of this report.

\section{Case report}

A 37-year-old female patient was admitted to the authors' surgery clinic due to a late gastric leakage in the form of a gastrocutaneous fistula after a bariatric procedure and after ineffective conservative treatment lasting over six weeks. In February 2019, the patient underwent sleeve gastrectomy for severe obesity and then in five days she required a reoperation due to a subphrenic abscess. During relaparotomy the anastomosis was not visualized due to adhesions and fibrin deposits. Therefore, the peritoneal cavity was only irrigated with a normal saline solution and a drain under the diaphragm was left. In the next two days discharge consisting of pus and gastric content appeared in the drain and Gastrografin swallow confirmed staple line dehiscence close to the cardia. However, despite the drainage of anastomotic dehiscence, total parenteral nutrition, and appropriate antibiotics, a leak in an amount of $200 \mathrm{ml}$ of gastric content and saliva remained. After admission of the patient to the hospital the endoscopic assessment revealed disruption of the esophagogastric anastomosis transforming into a fistula with a diameter less than $1 \mathrm{~cm}$ (Fig. $1)$. 


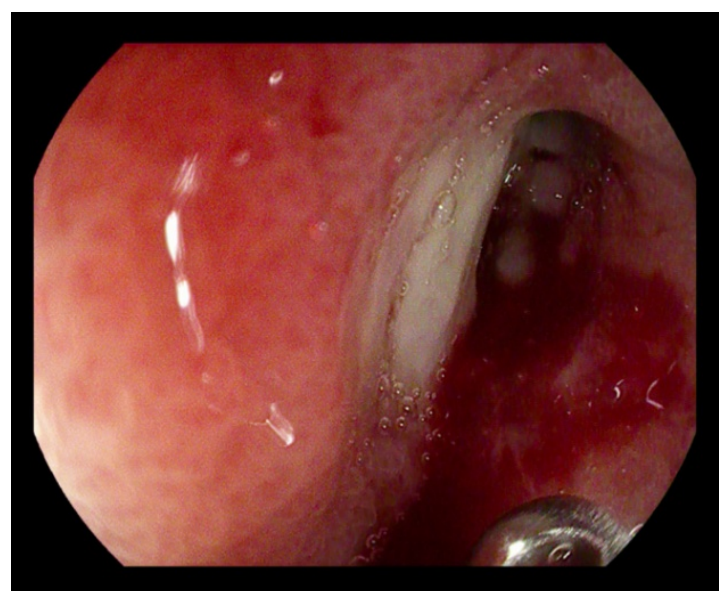

Fig. 1. Dehiscence of the anastomosis with a gastrocutaneous fistula in the suture line

After decision to apply E-VAC therapy a nasogastric catheter wrapped at the tip with a polyurethane foam (Vivano ${ }^{\circledR}$ Med Foam), with a diameter less than the dehiscence and a length of about $2 \mathrm{~cm}$, was introduced with endoscopic measures into the gastrocutaneous fistula filling it almost completely (Fig. 2).

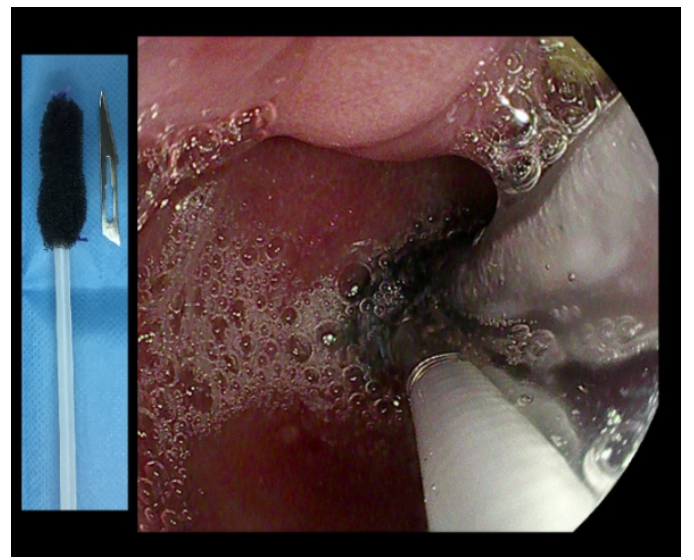

Fig. 2. E-VAC insertion: a nasogastric catheter wrapped with a polyurethane sponge is placed into the gastrocutaneous fistula canal

That catheter was connected with a vacuum generator (Renasys EZ Plus, Smith \& Nephew Medical, Hull, UK), and a stable negative pressure of $70 \mathrm{~mm} \mathrm{Hg}$ was maintained throughout the treatment. E-VAC was changed six times every fifth or sixth day, and during each change either the diameter or length of the sponge was reduced. As a result, shrinkage of the fistula was achieved, and its lumen filled with a fresh granulation tissue. Simultaneously with vacuum therapy a high-pressure Redon drainage of the fistula through the external opening was applied. Thus, after five weeks of treatment, gastric secretion was reduced from around $200 \mathrm{ml}$ per day on admission to 15-20 ml. However, further E-VAC therapy did not result in complete closure of the fistula and still a small amount of discharge maintained. The presence of leakage was confirmed by air passage during endoscopy and an outflow of orally administered dye (Fig. 3). For this reason, seven days after changing the last vacuum dressing, the decision was made to close the fistula with a fibrin sealant (Tisseal, Baxter AG, Viena, Austria).

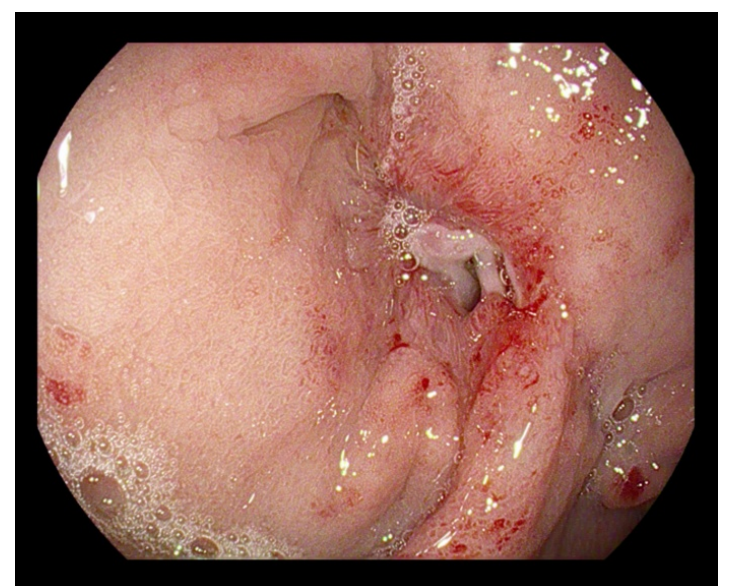

Fig. 3. Endoscopic evaluation after completed E-VAC therapy. Fistula channel significantly reduced and filled with a granulation tissue

A commercially available kit consisted of freeze-dried fibrinogen and aprotinin solution and freeze-dried thrombin and calcium chloride in a pre-filled syringe. After preparation according to the manufacturer's instructions the sealant, in the amount of $2 \mathrm{ml}$, was introduced into the lumen of the fistula through a single use polyurethane naso-gastric tube (Flocare ${ }^{\circledR}$ PUR ENFit Naso-Gastric Tube), which was previously inserted into the fistula canal (Fig. 4).

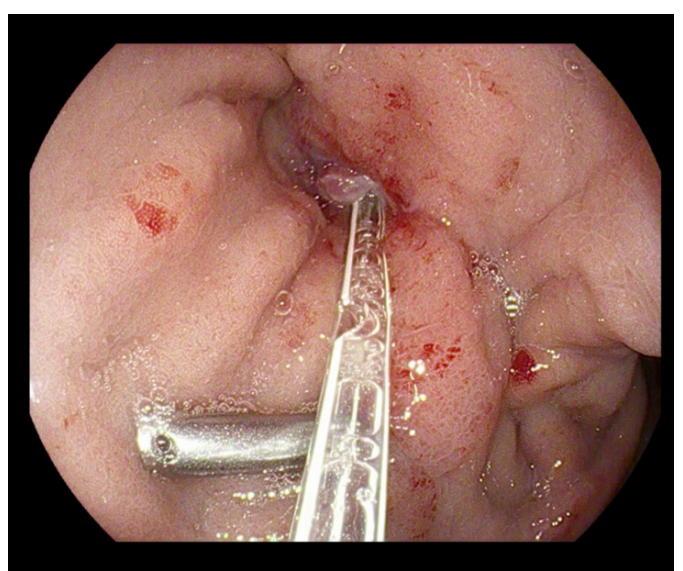

Fig 4. Fibrin sealant introduced into the fistula canal through a nasogastric tube

The conservative surgical treatment was combined with enteral immunomodulatory nutrition through a nasojejunal tube, enriched with L-glutamine, L-arginine and medium chain triglycerides to prevent the patient from hypoalbuminemia and lymphopenia. Basal metabolic rate was evaluated according to European Society for Parenteral and Enteral Nutrition (ESPEN) including anthropometric grade and laboratory tests e.g.: BMI 32, albumin serum range $2.88 \mathrm{~g} / \mathrm{dL}$, lymphocyte blood count $0.77 \mathrm{~K} / \mathrm{uL}$ and TIBC $210 \mathrm{ug} / \mathrm{dl}$. Finally, fistula was completely healed in 81 days, including 34 days of E-VAC treatment combined with final application of fibrin sealant. Patient was put on oral fluids second day after sealant application, and on normal diet the third day after application. Discharge through the Redon abdominal drain ceased just after the sealant introduction and it was removed following ultrasonographic assessment on the third day after the procedure. Endoscopic examination performed in 6 weeks 
from sealant application showed complete healing of the fistula (Fig. 5). Weight loss of the patient, from sleeve gastrectomy to the fistula healing, was estimated on $18 \mathrm{~kg}$ (14\% of body weight).

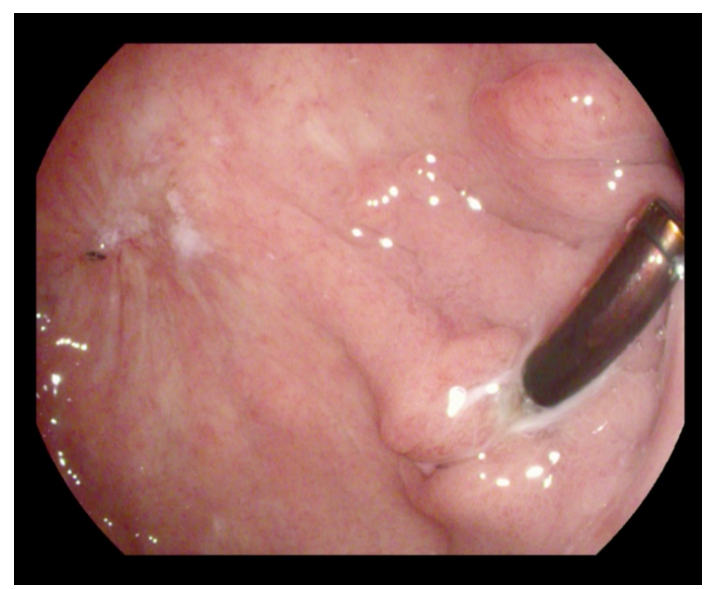

Fig. 5. Follow-up gastroscopy: assessment of the anastomosis line revealed a small scar at the site of the previous fistula

\section{Discussion}

The rate of leakage after sleeve gastrectomy is estimated from $0 \%$ through 20\% (Márquez et al., 2010), whereas mortality because of it varies between 0,12 and $0,14 \%$ (Chang et al., 2018). The type of leakage and dedicated therapy is determined according to the Csendes et al. (1990) and Burgos et al. (2009) classification dedicated to leaks after gastric surgery or classification of anastomotic leaks within the esophagus according to Consensus for Defining and Reporting Complications After Esophagectomy reached by Esophagectomy Complications Consensus Group (Low et al., 2015). As a result, leak can be classified according to the time of onset, clinical presentation, location, and radiologic signs. Both in type I according to Csendes and in type II according to ECCG, either a stent implantation or endoscopic vacuum assisted closure (E-VAC) is recommended, and supported by percutaneous drainage of pus collections (Low et al., 2015). E$\mathrm{VAC}$ is today a recognized method for the treatment of dehiscences within the digestive tract, showing even its higher effectiveness compared to stenting (Hwang et al., 2016). In turn, application of fibrin sealants for the treatment of digestive tract dehiscences are of experimental nature, and it has been reported in casuistic cases so far. Fibrin sealant was successfully applied according to Papavramidis for gastrocutaneous fistulas after vertical gastroplasty (MacLean procedure) in two patients, and after bilo-pancreatic diversion with duodenal switch (Marceau technique) in three patients. That sealant was introduced in a few sessions via a doublelumen catheter passed through the biopsy channel of a gastroscope (Papavramidis et al., 2008). The primary indications for the use of fibrin sealant are both hemostasis and sealing. It supports the end stage of clotting process as well as promotes the growth of fibroplasts and endothelial cells. As a result, a fresh granulation tissue is formed, rich in collagen and an extracellular matrix that fills tissue defects and deep interstitial spaces. (Limura and Giordano, 2015; Mullens et al.,
2019). Due to reduction of drainage volume and edema FS is widely used in reconstructive and plastic surgery as a factor supporting wound healing and fixation of skin grafts (Langer et al., 2015). In gastrointestinal surgery, it has been used since the 1990s mainly to close anal fistulas and to enhance intestinal anastomoses. Tisseal is also beneficial in endoscopy, especially in the treatment of GI fistulas, limited perforations or early anastomotic ruptures (Yang and Chen, 2015). Although, the opponents indicate that FG promotes inflammation and reduces bacterial phagocytosis shrinking, low-out put GI lesions can be successfully treated. (Rotstein et al., 1986; Nordentoft et al., 2015).

In conclusion the presented case shows that E-VAC combined with fibrin sealant application and Redon drainage through the external orifice improve the healing process of an anastomosis dehiscence within the digestive tract. That procedure can be indicated as a treatment of choice for intermediate and late dehiscences and fistulas within the digestive tract. That method however requires further prospective studies in a larger number of patients.

\section{Conflict of interest}

None to declare.

\section{Acknowledgments}

None to declare.

\section{References}

1. Borejsza-Wysocki, M., Szmyt, K., Bobkiewicz, A., Malinger, S., Świrkowicz, J., Hermann, J., Drews, M., Banasiewicz, T. 2015. Endoscopic vacuum-assisted closure system (E-VAC): Case report and review of the literature. Wideochir Inne Tech Maloinwazyjne. 10, 299-310.

2. Burgos, A.M., Braghetto, I., Csendes, A., Maluenda, F., Korn, O., Yarmuch, J., Gutierrez, L., 2009. Gastric leak after laparoscopicsleeve gastrectomy for obesity. Obes. Surg. 19(12), 1672-1677.

3. Campanile, F.C., Boru, C.E., Rizzello, M., Puzziello, A., Copaescu, C., Cavallaro, G., Silecchia, G., 2013. Acute complications after laparoscopic bariatric procedures: Update for the general surgeon. Langenbecks Arch. Surg. 398(5), 669-686.

4. Chang, S.H., Freeman, N.L.B., Lee, J.A., Stoll, C.R.T., Calhoun, A.J., Eagon, J.C., Colditz, G.A., 2018. Early major complications after bariatric surgery in the USA, 2003-2014: A systematic review and meta-analysis. Obes. Rev. 19(4), 529-537.

5. Csendes, A., Burdiles, P., Burgos, A.M., Maluenda, F., Diaz, J.C., 2005. Conservative management of anastomotic leaks after 557 open gastric bypasses. Obes. Surg. 15(9),1252-1256.

6. Csendes, A., Díaz, J.C., Burdiles, P., Braghetto, I., Maluenda, F., Nava, O., 1990. Classification and treatment of anastomotic leakage after extended total gastrectomy in gastric carcinoma. Hepatogastroenterology. 37(2),174-177.

7. Hwang, J.J., Jeong, Y.S., Park, Y.S., Yoon, H., Shin, C.M., Kim, N., Lee, D.H., 2016. Comparison of Endoscopic Vacuum Therapy and Endoscopic Stent Implantation with Self-Expandable Metal Stent in Treating Postsurgical Gastroesophageal Leakage. Medicine (Baltimore). 95, e 3416.

8. Langer, S., Schildhauer, T.A., Dudda, M., Sauber, J., Spindler, N., 2015. Fibrin glue as a protective tool for microanastomoses in limb reconstructive surgery. GMS Interdiscip. Plast. Reconstr. Surg. DGPW. 4, Doc14. 


\section{Cwaliński et al. / J Exp Clin Med}

9. Limura, E., Giordano, P., 2015. Modern management of anal fistula. World J. Gastroenterol. 21(1), 12-20.

10. Low, D.E., Alderson, D., Cecconello, I., Chang, A.C., Darling, G.E., D'Journo, X.B., et al. 2015. International consensus on standardization of data collection for complications associated with esophagectomy: Esophagectomy Complications Consensus Group (ECCG). Ann. Surg. 262, 286-294.

11. Márquez, M.F., Ayza, M.F., Lozano, R.B., Morales Mdel, M., Díez, J.M., Poujoulet, R.B. 2010. Gastric leak after laparoscopic sleeve gastrectomy. Obes. Surg. 20(9),1306-1311.

12. Mullens, C.L., Messa, C.A. 4th, Kozak, G.M., Rhemtulla, I.A., Fischer, J.P., 2019. To Glue or Not to Glue? Analysis of fibrin glue for split-thickness skin graft fixation. Plast. Reconstr. Surg. Glob. Open. 7(5), e2187.

13. Nordentoft, T., Pommergaard, H.C., Rosenberg, J., Achiam, M.P.,
2015. Fibrin glue does not improve healing of gastrointestinal anastomoses: A systematic review. Eur. Surg. Res. 54 (1-2), 1-13.

14. Papavramidis, T.S., Kotzampassi, K., Kotidis, E., Eleftheriadis, E.E., Papavramidis, S.T., 2008. Endoscopic fibrin sealing of gastrocutaneous fistulas after sleeve gastrectomy and biliopancreatic diversion with duodenal switch. J. Gastroenterol. Hepatol. 23 (12), 1802-1805.

15. Rotstein, O.D., Pruett, T.L., Simmons, R.L., 1986. Fibrin in peritonitis. V. Fibrin inhibits phagocytic killing of Escherichia coli by human polymorphonuclear leukocytes. Ann. Surg. 203(4), 413419.

16. Yang, H.Y., Chen, J.H., 2015. Endoscopic fibrin sealant closure of duodenal perforation after endoscopic retrograde cholangiopancreatography. World J. Gastroenterol. 21(45), 1297612980. 